\title{
Conceptual Analysis of Competency in Medical Education
}

\author{
Shahram Yazdani ${ }^{1}$ and Somayeh Akbari Farmad ${ }^{2 *}$ \\ ${ }^{1}$ Dean of School of Medical Education, Shahid Beheshti University of Medical Sciences, Tehran, Iran. \\ ${ }^{2} \mathrm{PhD}$ Candidate at School of Medical Education, Shahid Beheshti \\ University of Medical Sciences, Tehran, Iran. \\ http://dx.doi.org/10.13005/bbra/2039
}

(Received: 10 January 2016; accepted: 01 March 2016)

\begin{abstract}
Education system as a social institution like other similar institutions has changed and undergone substantial reforms. One of the most important reforms is focusing the systems and medical-education communities on competency issue and competencybased training. Despite the importance of this issue and the abundance of scientific literature on the competency, there is no consensus on its practical and theoretical definition so that the concept is complex and not transparent enough. In addition, no clear distinction is observed between this and similar and adjacent concept. Therefore, this study proposes an updated definition of competency using Hugh McKenna conceptual analysis to solve this ambiguity. According to the study, definition of competency is the ability to perform activities composed of knowledge (applied codified knowledge and tacit knowledge based on experience), technical and cognitive skills, and perceptual ability. This ability is habitual, endurable, task-relevant, observable, and measurable, independent, knowledge-based and context-dependent, and is considered as the main part of the job. Appropriate definition of the competencies can determine the criteria of excellent performance, forming a framework for future performance-based education, a basis for offering the certificate of competency, and strengthening social accountability. Competencies are developed through teaching and training under supervision, as well as reflective authentic experience
\end{abstract}

Key words: competency, competency-based education.

During the last three decades, education system as a social institution like other similar institutions has changed and undergone substantial reforms. One of the most important changes is the attention of systems and medical education communities to competency and education based on competency. The importance of this type of education is so much that Harden has introduced it as the most important trend in the last decade, and important medical education associations and organizations in the world have tried to offer models and frameworks about competency-based education.

In addition, organizations such as

\footnotetext{
* To whom all correspondence should be addressed. E-mail: akbarifs1@mums.ac.ir
}

ACGME and Royal college of physician and surgeon of Canada with its CanMEDS 2015 project are ready to introduce competency-based training as an Accreditation Standard in the near future ${ }^{2}$.

Despite the importance of this issue, and given that the word competency is used a lot in literature, there is no consensus on its practical and theoretical definition, the concept is complex and not transparent enough ${ }^{3,4,5}$. Moreover, reviewing texts has shown that not only there is no clear definition of this concept, but also in some cases, there is no clear distinction between this concept with concepts such as competency, performance, task, practice, activity, capability, meta-competency professional functioning, technical performance, procedure, function, and skill. Therefore, the present study aimed to identify 
internal structure of the competency and distinguish the basic components of the concept through the analysis of the concept to be able to give its operational and transparent definition.

\section{Method}

Concept analysis is a precise and formal process where it is tried to clarify, define, distinguish, and identify an abstract concept from similar concepts $6,7,8,9$. There are different approaches to carry it out like the ones introduced by (1989) Rogers, $(2005,1995)$ Walker and Avant, (1995) Morse, (2000) Swartz-Barcott and Kim, (1995) Hugh McKenna and (1997) Meleis.

In this study, Hugh McKenna's (1997) method was used to analyze the concept of competency. This concept analysis consists of nine steps including:

1. Selecting the desired concept

2. Defining the analysis objectives

3. Determining the meaning of the concept

4. Determining defining attributes of the concept

5. Identifying a model case

6. Introduction of alternative concepts including contrary, borderline, intermediate, and illegitimate

7. Considering antecedents and consequences of the concept

8. Considering the context and values

9. Determining empirical indicator of the concept $^{7}$

Literature review was conducted systematically and comprehensively in the common databases and related websites (Medline, Web of science, ...) using appropriate keywords including "competency", "competency based curriculum", "competency based education," "competency components," "competency characteristics," "competency purpose," "competency concept," "competency definition," and "competency concept analysis.” Further research was conducted using the search engine Google scholar, e-journals, ancestry search, and search in dictionaries. In combined search we used search terms in different databases; specific points in the search were observed

In the initial search, numerous articles were found, to eliminate unrelated resources, the first screening was done. The titles and abstracts of the retrieved records were studied and the relevant articles addressing competency concept in education were selected for further assessments. Finally, 52 documents became the basis of the analysis of the concept of competency. In this study, we continued to search literature until reaching saturation, so that no new features were found in the literature for competency. It should be noted that all studies involving any type of methodology, all years, different disciplines, and all types of available documentation, even weak in terms of methodology entered the study. Among the limitations of this search, using English articles and lack of access to some databases can be noted.

\section{RESULTS}

\section{Defining attributes of competency concept}

According to Walker and Avant, attributes of competency concept are the attributes that are often presented with the concept. These attributes are frequently offered in the literature with the concept making the concept unique and identifiable. By identifying the characteristics of the definition, the concept space shared with similar concepts decreased ${ }^{9}$.

In this step, by reviewing the literature on competency, we identified and categorized four conceptual areas for this concept, which include the purpose of competency, competency components, characteristics, and competency development (Fig. 1).

After stating the conceptual sphere of competency and its defining characteristics were determined based on literature review, at this stage, the necessity of each defining attributes should be assessed. For this purpose, we assess to see whether the defining characteristics can be used for opposite examples or not. If in checking, it is determined that this feature is also used for opposite examples, this is a wrong feature, and is deleted from our list. The next review is if we remove certain features from the list, will there be a problem to the definition of the concept of competency, if by removing the attributes of competency definition, it is made incomplete that feature is essential (the necessity test).

The proposed definition of the concept of competency

Based on the definition of characteristics determined in the previous step "Competency is 
Table 1: Empirical indicators of competency

\begin{tabular}{ll}
\hline Competencycomponents & Assessment methods \\
\hline $\begin{array}{l}\text { Codified knowledge } \\
\text { Tacit knowledge }\end{array}$ & $\begin{array}{l}\text { Oral, essay, MCQ, SAQ, PMP, EMI } \\
\text { Interview } \\
\text { Technical skill } \\
\text { Cognitive skill }\end{array}$ \\
& $\begin{array}{l}\text { KFP, Script Concordance, Chart Stimulated Recall } \\
\text { Perceptual ability }\end{array}$ \\
& $\begin{array}{l}\text { Perceptual ability is measurable, but in medical } \\
\text { domain, we don't have a test to measure it. }\end{array}$ \\
\hline
\end{tabular}

the ability, knowledge-based activities and jobs, which are the main components of the body of knowledge (applied encoded knowledge and tacit knowledge based on experience), skills (technical and cognitive) and cognitive ability. The person always, habitually, uses this ability to carry out his task at work. This activity is independent and not related to other activities, carrying it out needs mental activity that makes it distinct from the activities of a process that has concrete steps. Therefore it will be impossible to set a specific instruction for the individual to act on in all situations (often qualified in the proposed system is limited), since this activity and the ability to do it are easily measurable and the development of teaching and training under the supervision with the help of real experience with reflections is possible.

To ensure the achievement of its goal that is having excellent performance based on standards to strengthen social accountability, a framework for future job performance is usually determined and competency certification will be granted to those who receive training based on having this ability. Based on characteristics determined in the previous step "competency is the ability to perform activities composed of knowledge (applied codified knowledge and tacit knowledge based on experience), skill (technical and cognitive) and perceptual ability. This ability is habitual, endurable, task relevant, observable and measurable, independent, knowledge-based and contextual, and is considered as the main part of the job. Explaining the competencies leads to determining the criteria to excellent performance, forms a framework for future performance-based education, be the basis for offering the certificate of competency, and strengthening social accountability. Competencies are developed through teaching and training under supervision, as well as reflective authentic experience.

\section{Model case}

One model is a special example, in which competency concept is used and it must possess all the characteristics representing the concept. According to McKenna, by giving an example from real life as a "model" that represents all the characteristics of the concept, the degree of transparency and credibility of the concept increase ${ }^{7}$.

"One of the main activities expected from a faculty member is giving a lecture in the classroom, for which usually some standards have been established at the university level used to evaluate lecture quality. Lecture is an activity that requires knowledge and training skills (presentation, communication and interpersonal skills, questioning, active listening, etc) as well as long experience. Good presentation skill also depends on decision-making (for example, the amount, and how to engage the audience). An experienced teacher, based on his/her experience,

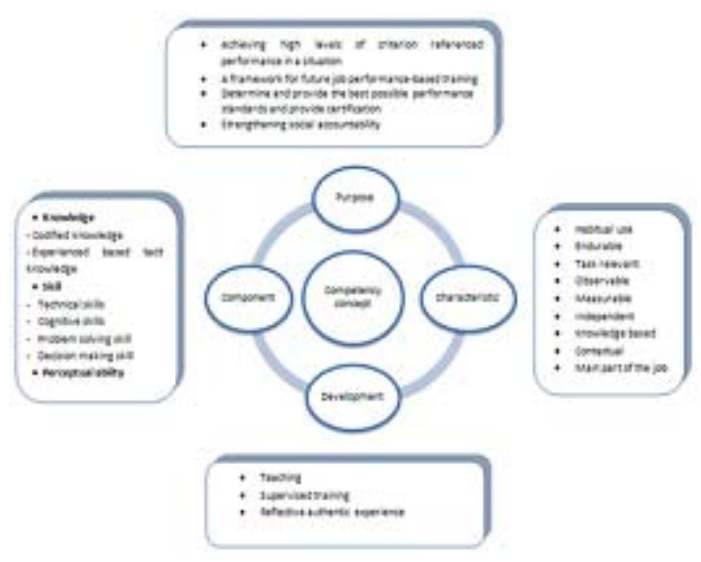

Fig. 1. Defining attributes of competency 
can usually lecture easily and quickly solve the existing problem and understand the reaction of the audience and get the attention they need to manage meetings. For example, while listening to questions or comments of audience to achieve their main points of interest, presenting lecture by experienced teachers becomes habitual, without stress, with minimal effort, and subjectivity.

Experienced teachers use different modes of lecture according to different background areas. Therefore, a fixed and similar guide for the lecture in terms of design and presentation cannot be offered and a part of good lecture needs good judgment of teacher. Developing the ability to give lecture requires learning knowledge, skill and experience. Therefore, the university has tried to design training packages, conduct courses to empower faculty members in the form of workshops, seminars, short courses and experiential learning as well as creating communities for experienced.”

\section{Alternatives}

Alternative issues include examples that are not based on the concept of competency. These may include contrary cases, related cases, borderline intermediate, and the illegitimate cases 7.

\section{The contrary case}

"One of the activities that are expected from a faculty member at the time of recruitment is giving lectures in the classroom, and this while, we know that the majority of newly recruited teachers do not have the experience of such activity before. Moreover, no specific framework for the presentation and subsequently evaluating on its basis not provided, and they have never seen and received knowledge either theoretically or practically teaching, training under supervision or reflective authentic experience in this field, and do not have command over its all aspects. Sometimes, in the first presentation sessions they face problems such as loss of the track of speech when the audience asks questions, the inability to control the order of class and get their attention, and the inability to respond. They usually pay no attention to audience reaction and just want to finish their lecture and are unable to impart the essence of the issue. Since they have never used skills such as attentive listening, using body language and so on, they are not usually very successful in these cases. Regardless of existing facilities and conditions that will happen, they try to follow the guidelines established in the text, while the formation of the competency of the speech involves the long experience under supervision and receiving constructive feedback.”

\section{Borderline issue}

Related borderline issues are those that have none of the characteristics defined in the concept of competency, but they seem similar like to psychomotor skills that are, in fact, one of the constituent elements of competency ${ }^{7}$.

\section{Intermediate cases}

The intermediate cases contain items that are very similar to the concept of competency, but lack some defined features of it ${ }^{7}$. These cases include: meta-competency, professional function, procedure, activity/duty, technical performance, professional competency.

\section{Illegitimate case}

This includes cases that reflect the concept of competency out of its real natural image ${ }^{7}$. These include cases that are not considered as competency but have the competency label.

For example, in job recruitments, the concepts of competency and general competency are usually considered as political and ideological standards of the individual that are irrelevant to the definition of competency with features and specifications we have in mind.

\section{Determining the antecedents and consequences}

The importance of this step is in the analysis of the arena where the concept is normally used $^{7}$. Antecedents are events before the concept. They cannot be considered as synonymous with the cause. The antecedent may help the incidence of the concept, may be associated with the incidence of the concept or its presence may be necessary for the presence of the concepts (getting out of balance) ${ }^{7}$. Walker and Avant (1995) believe that nothing can, at the same time, be both the antecedent and feature of the concept. Consequences are events or results that occur after the concept (returning to balance) ${ }^{9}$.

Antecedents of the concept of competency: responsibility, procedures, activities Concepts adjacent to competency concept: meta-competency, social identity, psychological identity, competency

Consequences of the competency 
concept: professional performance, competencybased curriculum, competency-based assessment

\section{Considering the context and values}

As mentioned in the previous section, concepts have different meanings based on the context they are introduced.

Considering that in our analytic definition of competency there are two defining characteristics: "being the main part of the job" and "excellent performance based on criteria" and since that definition, components, and the main criteria of competency and professional standards are different in different countries, therefore, our interpretation of the excellent performance will be different in different places. Therefore, with regard to the context and values in relation to a particular job, we can have different interpretations of competency.

\section{Empirical indices}

These include explicit reference to measure or evaluate the existence of the concept. This step is often considered as operationalizing of a concept. In other words, by being equipped with these indicators there is the possibility to see a concept "beyond the shadow of doubt." In some cases, the empirical indices include the features defined in Step $4{ }^{7}$. However, according to the Walker and Avant (1995), sometimes the concept is so abstract that even features defined are abstract and as a result cannot be good empirical indicators. Such indicators are useful for research and performance because they can provide criteria by which a concept can be measured ${ }^{9}$.

The purpose of this stage is to see whether in the technical discussion of the concept, we have operationalized the concepts enough so that it gets away from being abstract state and becomes objective, operational, and measurable.

Column of Table 1 suggests that the concept of competency has been broken into constituent parts to an extent , which is measureable.

\section{CONCLUSIONS}

The offered definition provides a broad theoretical understanding in connection with what competency is, what goals and characteristics it has, what component it is made up of, and how it develops. Given the importance of competencybased training and the emphasis put on it by major medical education institutions in recent decades, the need for modification in the curriculum and the design of competency-based curriculum is clearly seen. In this regard, the result of this conceptual analysis can be used as a guide for curriculum designers, teachers, evaluators, and administrators of educational institutions. It is clear that further research is needed in the field of how competencybased education should be and what differences it should have with the current training and what features should a competency-based curriculum model have.

\section{REFERENCES}

1. Kelly, Albert Victor. The curriculum: Theory and practice. Sage, 2009.

2. Ladhani, Moyez. The mini milestones assessment (mini-mas), a direct observational tool to assess clinical milestones in the era of competency-based education. Diss. 2015.

3. Axley, Lawrette. "Competency: a concept analysis." Nursing forum. Blackwell Publishing Inc, 2008; 4394).

4. Watson, Roger, et al. "Clinical competency assessment in nursing: a systematic review of the literature." Journal of advanced nursing 2002; 39(5): 421-431.

5. Markus, L., H. C. Thomas, and Keith Allpress. "Confounded by competencies? An evaluation of the evolution and use of competency models." New Zealand Journal of Psychology 2005; 34(2): 117.

6. Morse, Janice M., et al. "Concept analysis in nursing research: a critical appraisal." Research and Theory for Nursing Practice 1996; 10(3): 253-277.

7. McKenna, Hugh P. Nursing theories and models. Psychology Press, 1997.

8. Schwartz-Barcott, Donna, and Hesook Suzie Kim. "An expansion and elaboration of the hybrid model of concept development." Concept Dev Nurs Found Tech Appl 2000; 2: 161-92.

9. Walker, L. O., and K. C. Avant. "Concept analysis." Strategies for theory construction in nursing 2005; 3: 37-54. 